\title{
CASE
}

or

\section{CYNANCHE LARYNGEA.}

\author{
By Dr. ARNOLD,
}

OF STAMFORD.

COMMUNICATED

By Dr. BAILLIE.

Read Dec. 9, 1817.

Mr. boughton, farmer, of Cliffe, a village about eight miles from this place, was at a woodsale on Thursday, January 16,1817, where he supposes himself to have caught cold. He was, however, so well as to go to Stamford market the following day (Friday the 17th.) He returned home and drank tea with his family. After tea he called upon and spent some hours with a neighbour, with whom he took some rum and water. Upon returning to his own house he ate some meat supper with his family, and drank after it some warmed ale. In the night he complained of feeling rather sore in the throat. This feeling of soreness in the throat increased during the follow. 
ing day (Saturday the 18th), and about 3 o'clock in the afternoon of that day he first saw his apothecary, who ordered him the common remedies for a slight sore throat. About 9 o'clock that evening, when gargling, he first felt an inability to swallow; in his efforts to do which, and to continue to gargle, he was seized with a severe spasm of the muscles of deglutition, and this was immediately followed by a similar spasm of the chest; and such a distressing sense of suffocation was produced, that he seemed to be threatened with instant death, called for the window to be opened, and at length went into the yard, where he leaned in the greatest agony over some paling, expecting every moment to breathe his last.

This paroxysm, which was most alarming to himself and the by-standers, continued with the utmost violence for full two hours. About ten ounces of blood were taken away by the apothecary, and the paroxysm at length subsided. A messenger was immediately dispatched for me, and $I$ arrived at his house about one o'clock in the morning, (Sunday, Jan. 19th.)

I found him sitting up. He complained of sore throat, and said that he could not swallow any thing, as (to use his own expression) "c his throat was stopped up." Upon inspection, there was no appearance of inflammation or tumor of the tonsils, uvula, or velum pendulum palati : the ap- 
pearance of the fauces was quite natural. I endeavoured to depress the root of the tongue, and at the same time to pull it forward, so as to get a sight, if possible, of the epiglottis : but he could not bear the least pressure there, and said that the spoon touched the diseased part, which was exquisitely painful, and which appeared to him (to use his own expression) to be "pulling out" in the attempt that I was making to examine it.

His voice was very hoarse, but little louder than a whisper; and he was constantly spitting up a tough gelatinous mucus. His pulse was about 110 , of moderate strength, and his skin rather hot.

When asked where he felt pain, he pointed to the situation of the thyroid cartilage; said that his throat was stopped up there, and that he should never swallow again. Upon inspecting the blood that had been drawn at 9 o'clock, I found it one moderately firm coagulum, without any buffy coat, or any separation into serum and crassa. mentum.

A small quantity of fluid was now given him to swallow, but it was forcibly rejected through the nostrils; and the effort to effect deglutition produced a violent spasm, which was followed by sickness, and the vomiting of green bile. 
Being convinced from a consideration of all the symptoms, that $\mathrm{I}$ had a very serious case of $\mathrm{Cy}$ nanche Laryngea to deal with, and that consequently no time was to be lost, I directed that the patient should be blooded immediately in my presence. When about twenty ounces of blood had been taken away, there was a strong tendency to deliquium, and I ordered the arm to be bound up. When he had a little recovered, I inquired about the pain of the throat, which he said was much abated. Thinking this a very favourable opportunity for him again to try to swallow, and being anxious to get down a dose of submuriate of mercury as quickly as possible, I got ten grains of this medicine mixed up in a small quantity of the juice of preserved damascenes. I desired him to put it very quietly into his mouth, to let it remain there, and, without making any violent effort to swallow it, to wait and see if he could not catch an opportunity of doing so without any straining. After he had retained it some few minutes in his mouth, I encouraged him to try cautiously if he could not swallow it. He did so, and got down a part; and upon a second attempt the remainder; but not without inducing a paroxysm of the dyspnoea, and sense of suffocation, followed by nausea, and a sensation of the medicine being still sticking in his throat.

Encouraged by this result, so far favourable, I directed a purgative enema to be immediately in- 
jected, with the view of relieving a distressing sense of fulness which he felt in the lower bowels; and at the same time I ordered the calomel to be repeated every four hours in ten grain doses.

Before I left him, the throat was again beginning to feel very sore, and he to complain that it would be stopped up, and that he should never swallow again. His pulse was now very feeble; and considering how rapidly the symptoms of debility had come on in similar attacks, I was afraid that another bleeding from the arm would not be borne. I therefore desired that leeches might be procured as quickly as possible; and that immediately upon their arrival, at least a dozen should be applied to the upper part of the trachea ; afterwards a blister to the sternum; and that a second purgative glyster should be thrown up in the course of four or five hours, unless the calomel should previously have acted upon his bowels.

It was about 3 o'clock in the morning when I left him; and upon my arrival at his house again about 11 o'clock the same morning, the following was his state : he complained of less pain of the throat, and though he said he could not swallow, he had got down another calomel powder, but with great difficulty. The glysters had brought away some freces, but there had been no purgative action; thirteen leeches had been applied, and the orifices were still bleeding; he spoke 
with less hoarseness, and his pulse had got down to 100 .

As it was now his time to take 2 thind powder, I was happy to witness his being able to do so with some degree of comparative facility, though not without many efforts, and the induction of the sense of suffocation to stine exvent: Fe opoplained that he felt almost as weak from the lows of llood from the leeches, as he had done from the veno section.

I left him at this visit with some small degree of hope ; and as I now placed wy nolinace chiefly upon the calomel, the spocific anect of which of on the valivary glands I wished to excite as apeedily as possible, I directed it still to be continued in ten grain doses at inturte of four hours 5 and also that the leeches should again be applied in the evening, if there was ent increace of pain, or if indeed there was not a still further abatement of it.

Monday, Jan. 20th. Upon my viaif this moming, it gave me great matistion to find my patient swallowing some ten with a degree of eomfort. His throat was much easier then the day before, thengh still in pain. The cabisel had acted upon his bowels, and brought away a great deal of fotid dark green bile. There was a tendency to ptyalism, and he complained much of 
his gums feeling tender. An equable warmth was diffused over the surface of his body; the appearance of his countenance was good; the pulse about 110, of moderate strength; and the tongue slightly coated. I directed saline draughts, with a small quantity of liquor antim. tartariz.; thin milk porridge or tea for his diet; and that a dose of jalap should be given early the next morning, and be repeated if necessary: also that leeches should be again applied to the upper part of the throat; and that if the pain continued, they should be a second time used previously to my next visit, which was not to take place till after an interval of a day, unless a recurrence of unfarourable symptoms should make it necessary to send for me sooner. The calomel was to be discontinued.

Wednesday, Jan. 22d. I now found my patient quite convalescent. A considerable ptyalism had obtained for the last two days. All pain was removed; the power of swallowing was recovered; the voice was natural ; and all his feelings comfortable : and from this time he had no return of any unpleasant symptoms, but gradually recovered a state of better health than he had enjoyed for some time before this serious attack.

Stamford, Oct. 25th, 1817. 